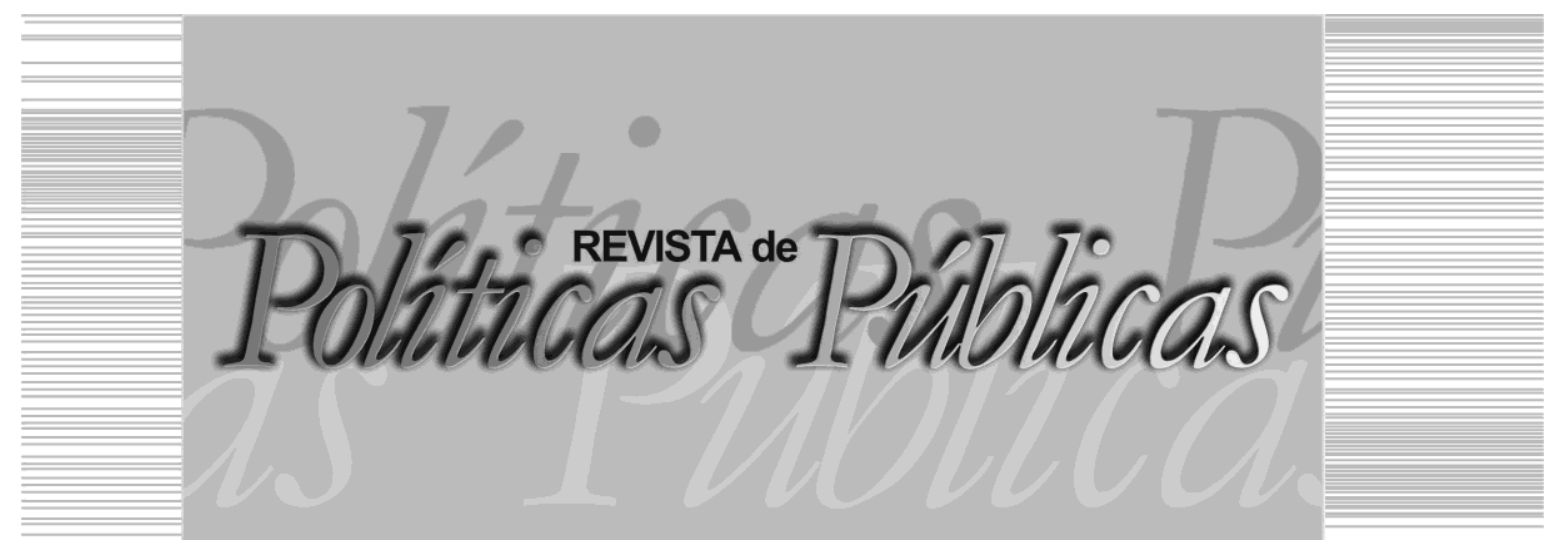

\title{
DISTRIBUIÇÃO ESPACIAL E ACESSO A SERVIÇOS PÚBLICOS ESSENCIAIS EM POLÍTICAS DE HABITAÇÃO DE INTERESSE SOCIAL
}

\author{
Manuela Maria Nascimento ${ }^{1}$ \\ Universidade Federal de Pernambuco (UFPE) \\ Diana Carolina Gómez Bautista \\ Universidade Federal de Pernambuco (UFPE) \\ Rogério Luiz Souto Cavalcanti ${ }^{3}$ \\ Colégio Fazer Crescer (CFC) e Colégio Madre de Deus
}

\section{Resumo}

Esta pesquisa avalia a provisão habitacional no âmbito da disponibilidade de serviços de educação e saúde pública para populações realocadas para conjuntos habitacionais, bem como a sua distribuição espacial na cidade do Recife, predominantemente condicionada por determinações de origem política e econômica. Nesse contexto, pode-se questionar: A política habitacional contraria o direito à cidade, levando em conta sua distribuição especial e deficiências na gestão do aumento das demandas

\footnotetext{
${ }^{1}$ Geógrafa, Doutoranda em Desenvolvimento e Meio Ambiente pela Universidade Federal de Pernambuco (UFPE), Bolsista Coordenação de Aperfeiçoamento de Pessoal de Nível Superior (CAPES). E-mail: manuelanascimento@yahoo.com.br

${ }^{2}$ Assistente Social, Doutoranda em Desenvolvimentoe MeioAmbientepela UFPE, Bolsista Fundação de Amparo à Ciência e Tecnologia do Estado de Pernambuco (FACEPE). E-mail: dianacaro.gomez@gmail.com / Universidade Federal de Pernambuco-UFPE: Av. Prof. Moraes Rego, 1235 -Cidade Universitária, Recife-PE.CEP:50670-901

${ }^{3}$ Geógrafo, Mestre em Desenvolvimento Urbano pela UFPE, Professor de Geografia da rede particular de ensino Colégio Fazer Crescer (CFC) e Colégio Madre de Deus. E-mail: cavalcanti_rg@yahoo.com.br / Colégio Fazer Crescer-CFC: Av. Santos Dumont, 1181, Rosarinho, Recife-PE. CEP: 52050-050; Colégio Madre de Deus: Rua Belmonte, 199, Boa Viagem-Recife-PE. CEP: 51030-490.
} 
por serviços públicos essenciais? Na busca por respostas, realizou-se uma revisão bibliográfica e documental, observação direta em campo e análise por meio de geoprocessamento. Verificou-se que a implantação dos conjuntos não é acompanhada pela melhoria na distribuição dos serviços de educação e saúde, sendo condicionada por decisões políticas de natureza financeira e não pelo aumento da demanda social.

Palavras-chave: Políticas Públicas, conjuntos habitacionais, direito à cidade, Recife.

\title{
SPACE DISTRIBUTION AND ACCESS TO ESSENTIAL PUBLIC SERVICES IN SOCIAL INTEREST OF HOUSING POLICIES
}

\begin{abstract}
This research evaluates the housing provision in the scope of the availability of education and health public services for populations relocated to housing estates, as well as their spatial distribution in the Recife city, predominantly conditioned to determinations of political and economic origin. In thiscontext, it may be questioned: Does the housing policy it is contrary to the right to the city, taking into account its spatial distribution and deficiencies in the management of the increase in the demand for essential public services? In the search for answers, it was made a bibliographic and documentary review, direct obser- vation and analysis through geoprocessing. It was verified that the implantation of the housing estates is not accompanied by an improvement in the distribution of the education and health services, being conditioned by political decisions of a financial nature and not by the increase of the social demand.

Key words: Public Policies, housing estates, right to the city, Recife.
\end{abstract}

\section{INTRODUÇÃO}

No sentido de diminuir os efeitos do processo de formação historicamente desigual do espaço urbano (VASCONCELOS, 2004), tem ocorrido no Brasil a implementação de políticas públicas de caráter integral, englobando ações em habitação, saneamento e infra-estrutura urbana de uma forma geral. As intervenções são oriundas principalmente do Programa de Aceleraçãodo Crescimento (PAC), nas suas modalidades Saneamento e Urbanização de Assentamentos Precários. No caso da cidade do Recife, Pernambuco, as obras contemplam, sobretudo, a recuperação de áreas ambientalmente de-gradadas situadas às margens dos rios Capibaribe e Beberibe e a ampliação da infraestrutura viária. 
$\mathrm{Na}$ maioria das intervenções, a remoção de comunidades pobres faz parte dos projetos para realização das obras, o que ao longo do tempo tem acompanhado o processo de formação socioespacialdacidade. Desse modo, não apenas no context recente, a população mais pobre vem sendo deslocada de seus locais de origem, fato que comumente gera disputas por partes do território recifense. Nesses embates, normalmente prevalece a realocação de comunidades, ou parte delas, mesmo que as famílias não recebam novas casas, não recebam moradias com um bom padrão de habitabilidade ou permaneçam em situações provisórias, como o recebimento de auxílio-moradia.

Para Silva (2015, p. 540), ocorre em Recife uma omissão administrativa continuada, associada a processos de gentrificaçãoe especulação imobiliária, os quais ocorrem abusivamente também no plano institucional, fazendo do tratamento do solo urbano "[...] um mero conteúdo monetário acessível a poucos."

Devido à baixa capacidade de mobilização formal dessas famílias e tendo reduzida ou nenhuma influência nas instâncias do poder administrativo, ocorrem remoções e realocações em benefício do que o Estado, utilizando-se de seu poder de decisão e coerção, institui como obras de utilidade pública, que em tese beneficiariam uma parcela maior da população do que aquele grupo removido do local. Diante desse conveniente mecanismo, ao qual também se associa o elevado poder empresarial na construção e reconstrução de espaços urbanos, restam às políticas de habitação de interesse social proporcionar as diretrizes e ações que minimizem os inevitáveis transtornos.

Frente ao quadro brevemente apresentado, surgem questionamentos acerca dos eventos observados em obras desse porte. Dessa forma, diante da urgência dos empreendimentos urbanísticos ou ambientais, as ações governamentais direcionadas à provisão de habitação social conseguem reintegrar territorialmente as populações removidas e garantir o direito à cidade ou apenas alojam algumas famílias em conjuntos habitacionais? Os programas de habitação de interesse social seriam uma solução fácil da equação entre a pouca existência de solo urbano para expansão do capital empresarial e a referida omissão por parte do poder público diante de suas atribuições na garantia da função social da cidade? A política habitacional contraria o direito à cidade, levando-se em conta as deficiências na gestão do aumento das demandas por serviços públicos 
essenciais?

Levando em conta a complexidade de tais questões, tentou-se caminhar para além dos exercícios de reconstituição dos fatos consumados no território, realizando um enfoque espacializado dessa provisão e suas relações com o entorno, a fim de elucidar a possibilidade de satisfação, ou não, de demandas sociais para populações realocadas. Reconhecendo esse processo como resultante de um nítido desequilíbrio entre as relações de poder existentes no confronto entreo Estado, os setores empresariais e a população de baixa renda, espera-se fornecer indicadores para o acompanhamento de como o poder politico determina a tomada de decisões sobre a configuração territorial.

Sendo assim, observou-se a distribuição geral dos conjuntos habitacionais em políticas de habitação de interesse social nos últimos quinze anos (2001 a 2016) no território recifense, além de sua interface com os serviços públicos de saúde e educação. Esta interface entre as políticas públicas realizou-se mais especificamente em projetos de habitação financiados pelo PAC, realizados na Bacia Hidrográfica do Rio Beberibe (BHRB), que abrange a maior parte da Zona Nortedo Recife. As obras neste local incluem a retirada de palafitas e de moradias precárias desprovidas de serviços essenciais às margens do Rio Beberibe, para implantação de saneamento, drenagem e pavimentação, além da construção de unidades habitacionais para realocação de famílias.

\section{DELINEAMENTO METODOLÓGICO DAPESQUISA}

Primeiramente realizou-se uma pesquisa bibliográfica para discutir o andamento geral das políticas habitacionais brasileiras no contexto recente, além da análise de documentos sobre o PACe sua implantação na regularização das áreas na bacia do Rio Beberibe. A pesquisa bibliográfica e documental foi realizada nas bibliotecas e departamentos da Universidade Federal de Pernambuco (UFPE), além de portais eletrônicos, tais como o Banco de Teses e Dissertaçõesda Capes, a Biblioteca Eletrônica Scielo, Revistas Científicas, Jornais Digitais e Anais eletrônicos. Paralelamente, foram realizadas consultas a funcionários da Prefeitura da Cidade do Recife (PCR) e a observação direta em campo, com a finalidade de coletar e verificar informações sobre o andamento do PAC-Beberibe. 
DISTRIBUIÇÃO ESPACIAL E ACESSO A SERVIÇOS PÚBLICOS ESSENCIAIS EM POLÍTICAS DE HABITAÇÃO DE INTERESSE SOCIAL

$\mathrm{Na}$ análise especial do processo, foi gerada uma base vetorial com a localização, informações gerais e a delimitação dos conjuntos habitacionais e elementos do seu entorno. Também foram analisadas fotografias aéreas cedidas pela PCR e pela Agência Estadual de Planejamento e Pesquisa de Pernambuco (CONDEPE/FIDEM). Além disso, para finalização da etapa de geoprocessamento, foram observadas imagens de satélite referentes ao ano de 2016, obtidas por meio do aplicativo Google Earth PRO. Essas imagens de satélite mais recentes serviram de base para a identificação e localização dos conjuntos habitacionais.

Para a correlação entre a localização dos conjuntos habitacionais e a situação dos serviços de saúde e educação públicos, foram utilizadas as bases de dados disponíveis no portal eletrônico oficial da PCR. Para essa análise, fundamentamos como critério duas distâncias, tomando como base os aglomerados de conjuntos habitacionais, o primeiro raio leva em consideração os serviços localizados a um quilômetro, e o segundo, a um raio de dois quilômetros, a fim de avaliar a distância no acesso a esses serviços pelos habitants dos conjuntos.

Para fins de representação, não aparecem nos mapas todas as áreas formadas pelos raios estabelecidos para cada conjunto, uma vez que prejudicaria a visualização devido à escala. Dessa forma, os círculos correspondem a dois conjuntos habitacionais que abrangem duas áreas de concentração. Da mesma forma, apresentamos uma visão geral relativa às distâncias encontradas para cada conjunto habitacional, ao invés de focar na descrição quantitativa dos dados encontrados. A localização geral da área em estudo e os conjuntos onde foi realizada a correlação entre políticas públicas, podem ser observados na Figura 1. 
Figura 1 - Localização da Bacia Hidrográfica do Rio Beberibe na Região Metropolitana do Recife e dos Conjuntos Habitacionais Construídos pelo PAC e PROMETRÓPOLE

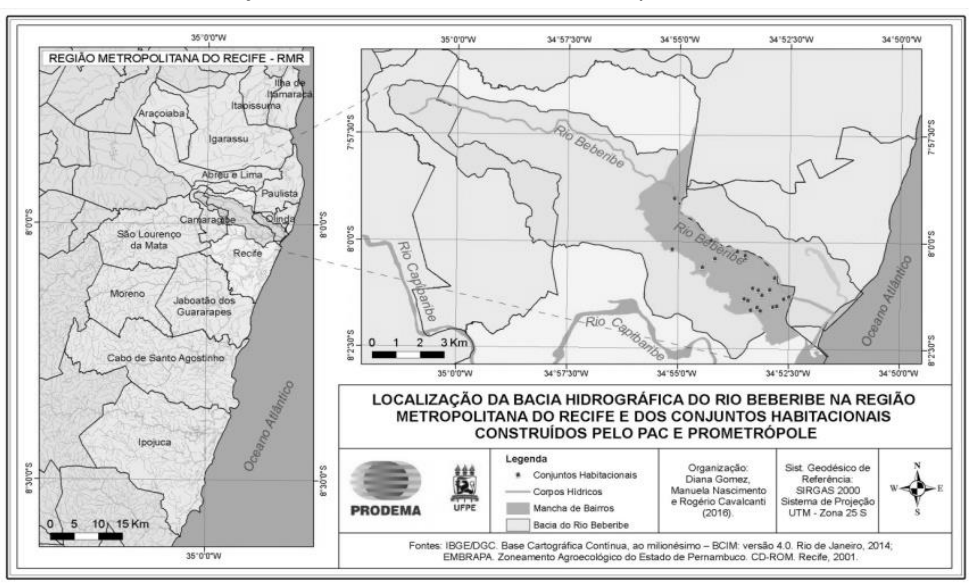

Fonte: Elaborada pelos autores (2016).

A área mais específica para análise foi selecionada, pois nela verifica-se a formação de um aglomerado de conjuntos habitacionais, em um local que já conta com uma elevada densidade populacional de pessoas com média a baixa renda, bem como uma expressiva e persistente quantidade de residências do tipo palafitas ao longo do rio e canais (Figura2).

Figura 2 - Rio Beberibe e seu entorno - Bairro Caixa d`Água, Recife/PE

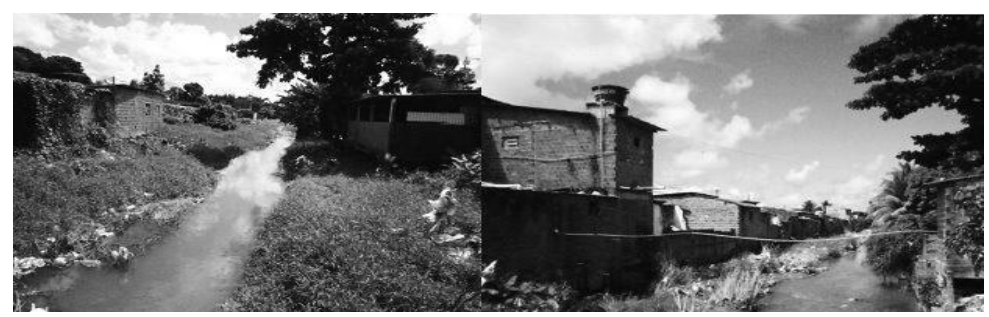

Fonte: Diana Bautista (2016).

Além do PAC-Beberibe, a região tem recebido intervenções do Programa de Infraestrutura em Áreas de Baixa Rendada Região Metropolitana do Recife (RMR) (PROMETRÓPOLE) e, devido à proximidade, também foram considerados três conjuntos habitacionais construídos por este programa e mais dois conjuntos construídos pelo PACSaneamento e Caixa Econômica Federal (CEF) em convênio com a PCR, chegando-se a umtotal de 22 conjuntos habi- 
tacionais. Dentre estes, 16 já foram inaugurados a partir do ano de 2008 (1926 unidades habitacionais - UH), cinco estão com as obras paralisadas (292 UH) e um encontra-se parcialmente inaugurado e em obras (89 UH entregues e 215 em construção).

\section{DIREITO À CIDADE, TERRITÓRIO E POLÍTICAS PÚBLICAS DE HABITAÇÃO SOCIAL}

O tema do direito à cidade vem transversalizando discussões sobre temas clássicos na produção do espaço urbano, debates sobre a efetividade de políticas públicas e a atuação de movimentos sociais. A consideração deste aspect torna-se emergente na medida em que ocorrem invariavelmente embates desiguais nas relações de poder entre os sujeitos que conduzem as decisões sobre o território. (BRUNO, 2009). Também implica numa direção contrária a desígnios da gestão pautados essencialmente no poder político, nos quais a tomada de decisões exclui parcelas da população.

Se por um lado, o direito à cidade ainda apresenta uma tendência a situar-se no plano da visualização de problemas e de reinvindicações, ao invés de efetivamente contribuir para a ocorrência de mudanças na redistribuição dos espaços e benefícios para todos os habitantes nas cidades, por outro ele manifesta forças que contribuem na busca por cidades mais equitativas. Postula-se que, por conta da existência de legislação pertinente (tanto os artigos $182 \mathrm{e}$ 183 da Constituição Federal como o seu desdobramento no Estatuto da Cidade, por exemplo), bem como por ser um conceito amplamente aceito e discutido em termos acadêmicos e práticos, o direito à cidade careça apenas de mais instrumentos que contribuam para sua legitimação, além da evidente ampliação de sua inserção na execução das políticas públicas.

Nesse sentido, considera-se importante as tentativas de espacialização de processos que envolvam a problemática do direito à cidade e a noção de território. Esta associação pode fornecer elos entre a produção e uso do espaço, as formas de poder político do Estado, do setor empresarial e demais grupos da sociedade. No caso específico dessa pesquisa, entre os interesses do setor empresarial por determinadas áreas e das populações a serem realocadas por meio de políticas de habitação de interesse social.

A movimentação e a fixação das pessoas no espaço geográfico, por meio da implantação de habitações, constituem 
um campo frutífero para o entendimento de como se dá a morfologia das cidades. $\mathrm{O}$ crescimento populacional, a intensa urbanização e os diversificados processos adjacentes à sua formação, também alteram e intensificam continuamente as dinâmicas dos assentamentos humanos. Além disso, considerando o comportamento do processo de ocupação em seu aspect temporal, têm-se evidências de como a cidade surgiu, desenvolveu-se e quais os possíveis rumos que ela terá.

Para RaRestin (1993), deve-se compreender que o espaço é anterior ao território, e se forma a partir dele como resultado de ações conduzidas por quaisquer atores que se apropriam concreta ou abstratamente do espaço, ou seja, o territorializando. O território é um local de relações inscritas em um campo de poder, uma produção realizada a partir do espaço, considerando todas as relações que o envolve, comum a referência implícita às noções de limite e delimitação, sendo estes traçados fisicamente ou não, e gerados a partir da ação de um grupo.

Outros fatores determinantes nesta dinâmica são: o modelo de gestão política adotado pelas administrações municipais e sua interface com a legislação estadual e federal; a qualidade e cumprimento da legislação urbanística; a efetividade da fiscalização e regularização fundiária e; a existência e cumprimento da legislação ambiental.

É importante destacar que esta relação crescimento populacional, rompimento de fronteiras e provisão de moradias na formação das cidades, não ocorre de forma linear, pois ocorre em sintonia com a produção do espaço geográfico em sua totalidade e complexidade. Sendo assim, acontece tanto pela demanda por novas áreas, como também se dá pela valorização de porções territoriais em detrimento de outras. Dá-se por reflexos de eventos políticos ou econômicos, bem como pela ação de movimentos sociais e de processos históricos associados aos dois casos.

Acontece ainda, de maneira autônoma, pela decisão de qualquer pessoa nas cidades. Do ponto de vista do habitante, esses fatores podem ser sintetizados em duas questões que determinam a tomada de decisão no processo: Quais as possibilidades de obtenção e manutenção da moradia? Quais as condições de infraestrutura, mobilidade e acesso a serviços no local da habitação? 
DISTRIBUIÇÃO ESPACIAL E ACESSO A SERVIÇOS PÚBLICOS ESSENCIAIS EM POLÍTICAS DE HABITAÇÃO DE INTERESSE SOCIAL

Na posição de provedor ou de consumidor da moradia, os habitantes planejam e decidem (no próprio local, ou distante do ambiente a ser construído); constroem (para eles mesmos ou para os outros a um determinado custo); residem (de acordo com oportunidades ofertadas e condições financeiras de obtenção, aluguel ou compartilhamento de imóveis); circulam pela cidade e; utilizam ou acessam os serviços e infraestruturas. Em todos os casos, a ação ocorre de forma desigual e ao mesmo tempo vinculada.

A contradição desigualdade-vínculo se dá uma vez que se formam arranjos nos quais, cada segmento da sociedade ou habitantes isoladamente, posicionam-se em uma mesma área, município ou na metrópole, de acordo com o seu grau de interesse e, sobretudo, de seu poder de ação diante das decisões a serem tomadas. O desequilíbrio nessas relações gera imposições verticalizadas e injustiças socioespaciais, e assim, constitui-se um quadro geral de desigualdades. Contudo, inevitavelmente, ações e reações dos indivíduos ou organizações, as causalidades e consequências destas decisões, tomadas democraticamente ou impostas de maneira autoritária (e por vezes arbitrária), irão reverberar no espaço e sociedade como um todo, daí a noção de vínculo.

De acordo com Santos (1997), a questão do espaço habitado pode ser abordada do ponto de vista biológico, levando-se em conta a adaptabilidade do homem como indivíduo diante das condições naturais ou, tal como se pretende neste estudo, por meio de uma abordagem na qual o ser humano modifica o ambiente urbano en- quanto agente político e social. Segundo Carlos (2003), o habitar implica um conjunto de ações que envolvem a vida realizada pela mediação do outro, imersa nas relações que constroem a história particular, mas que também é coletiva, pois nelainsere-se a história de cada indivíduo.

Dessa maneira, entende-se que as ações na gestão da habitação possuem um forte caráter territorial, que em sua complexidade, não pode ser considerado apenas um fator de redistribuição de locais de moradia, mas levar em conta as territorialidades envolvidas. A definição de territorialidade de Haesbaert (2007, p. 22) incorpora, além da dimensão política, as relações econômicas e culturais, considerando que ela está " [...] intimamente ligada ao modo como as pessoas utilizam a terra, como elas próprias se organizam no espaço e como elas dão 
significado ao lugar."

A concepção de que a implantação de habitações constitui-se um elemento genético e determinante na produção do espaço urbano, tem emergido fortemente desde meados do século passado. É neste período, conforme Santos (2005), que se dá o início da fase de urbanização corporativa no Brasil, empreendida apartir dos interesses de grandes firmas. Não apenas nas cidades brasileiras, mas em qualquer outra que experimentou ou experimente um crescimento demográfico, funcional, migratório ou financeiro, é necessária a provisão de moradias para suprir os novos contingentes populacionais.

Entretanto, a urgência na implantação de políticas públicas na área de habitação é marcada por conflitos socioambientais, produzidos a partir de um alheamento de representações sociais ao processo, mesmo em modelos de gestão no qual a participação de diversos atores sociais é instituída como regra. No caso das despossessões, tal como proposto por Harvey $(2012$, p. 82, grifo do autor), fica clara a conveniência higienista, por meio da qual as mudanças em determinadas porções do território deverão necessariamente passar por reconstruções que implicam no total desaparecimento de áreas pobres, e assim,

A absorção de excedente através da transformação urbana tem um aspecto obscuro. Ela tem acarretado repetidas contendas sobre a reestruturação urbana pela "destruição criativa", que quase sempre tem uma dimensão de classe já que é o pobre, o desprivilegiado e o marginalizado do poder politico que primeiro sofrem com este processo.

Para Souza (2001), o território possui escalas espaciais e temporais diferenciadas, não deve ser despolitizado e nem retirado de um contexto estratégico associado às sociedades complexas, tais como conflitos sociais objetivos e suas causas, além de responder pela produção do espaço.

Little (2002, p. 3) também leva em conta o fator político, colocando o "[...] fato de que um território surge diretamente das condutas de territorialidade de um grupo social implica que qualquer território é um produto histórico de processos sociais e políticos". Nesse sentido, a territorialidade seria "[...] um esforço coletivo de um grupo social para ocupar, usar, controlar e se identificar com uma parcela específica de seu ambiente biofísico, convertendo-a assim em seu 'território'." (LITTLE, 2002, p. 3, 
grifo do autor).

Evidencia-se neste sentido, o caráter político e estratégico que permeia o controle da provisão de habitações pelo Estado (NASCIMENTO; BAUTISTA, 2016), fazendo deste aspecto, um mote essencial nas campanhas eleitorais e governos até então. Na medida em que algumas áreas necessitam de requalificação urbana ou ambiental, são realizadas as grandes obras e o Estado exerce a função de resolver o problema de abrigar novamente as pessoas que deverão ser retiradas dos locais de interesse, respondendo assim, pelos novos arranjos territoriais.

Desse modelo, decorrem a intensificação de processos de segregação territorial, o aprofundamento e concentração de renda e o fortalecimento e consolidação do mercado imobiliário privado. (MARICATO, 2009). Além disso, as novas habitações inserem-se em processos de periferização. Rolnik e Nakano (2009) destacam os eventos que podem ser verificados na implantação dos programas habitacionais: seu posicionamento nas terras mais baratas, sem acesso a infraestruturas de saneamento básico, transporte coletivo, equipamentos comunitários de educação, saúde, lazer e cultura.

Essa situação, de acordo com Leitão e Araújo (2013), faz com que provisão de habitações permaneça nos moldes da política praticada no Brasil em tempos do Banco Nacional de Habitação (BNH) e que até hoje é duramente criticada por diversos autores, pois teve como desdobramentos, uma grande diversidade de problemas para os moradores beneficiados e para as cidades, que tardaram em ser solucionados, ou até hoje não foram.

Fica claro diante dos problemas observados no contexto de produção das habitações de interesse social, que não se deve considerar o fenômeno habitacional como resultado de um processo alheio a aspectos inerentes da individualidade, ambiente ou coleti- vidade. O desafio se apresenta, quando a tomada de decisão sobre o ato de morar em alguma porção do espaço, ainda está muito longe de ser uma questão coletiva, na qual se considere a devida importância do direito à cidade.

Essa produção e gestão, contemplando poderes políticos em desequilíbrio, ora está centrada no individualismo, aspirações de consumo ou desígnios do Estado e mercado imobiliário, ora 
está condicionada por desigualdades socioeconômicas e injustiças sociais. De forma igualmente conflitante, o território vai distanciando-se de ser uma construção coletiva, apesar de ser, inevitavelmente, o ambiente de todos.

\section{RESULTADOS E DISCUSSÃO}

Pensando no habitar a cidade, os dissensos anteriormente mencionados emergem mais intensamente, considerando áreas com a ocorrência de altas densidades demográficas e a constant disputa por espaços. Na medida em que essa disputa tem como determinante a capacidade de intervenção de agentes de acordo com seu poder financeiro, resta às populações que estão à margem da tomada de decisões quanto à sua posição no espaço urbano, sofrer as consequências das intervenções associadas ao capital empresarial. Nesse sentido, Harvey (2012, p. 74) posiciona a questão a partir da noção de liberdade, afirmando que

A questão de que tipo de cidade queremos não pode ser divorciada do tipo de laços sociais, relação com a natureza, estilos de vida, tecnologias e valores estéticos desejamos. O direito à cidade está muito longe da liberdade individual de acesso a recursos urbanos: é o direito de mudar a nós mesmos pela mudança da cidade. Além disso, é um direito comum antes de individual já que esta transformação depende inevitavelmente do exercício de um poder coletivo de moldar o processo de urbanização. A liberdade de construir e reconstruir a cidade e a nós mesmos é, como procuro argumentar, um dos mais preciosos e negligenciados direitos humanos.

Contudo, um problema subjacente emerge: Para chegar a essa forma de liberdade, no contexto de deficiência do acesso a recursos urbanos básicos que ainda é verificado no Brasil, o direito à cidade teráde passar ainda por outros estágios que se relacionam ao acesso a serviços e infraestruturas essenciais ao bem-estar humano. Não que os dois movimentos não possam ocorrer simultaneamente, os dois são imprescindíveis e complementam-se, porém, a dificuldade se apresenta em incorrer-se por um caminho que vise um fim distan- te das carências vivenciadas, sobretudo pelas populações em maior estado de precariedade com relação ao ambiente e suas habitações (Figura 3). Daí é importante reiterar a citação de Harvey (2012), pois nela encontra-se este espaço para discutir mudanças efetivas, não deixando apenas de destacar, que o direito à cidade não pode negligenciar a premissa do acesso a recursos urbanos. 
Figura 3 - Condições internas e do entorno de habitações do tipo palafita às margens do Rio Beberibe -Zona Norte do Recife/PE

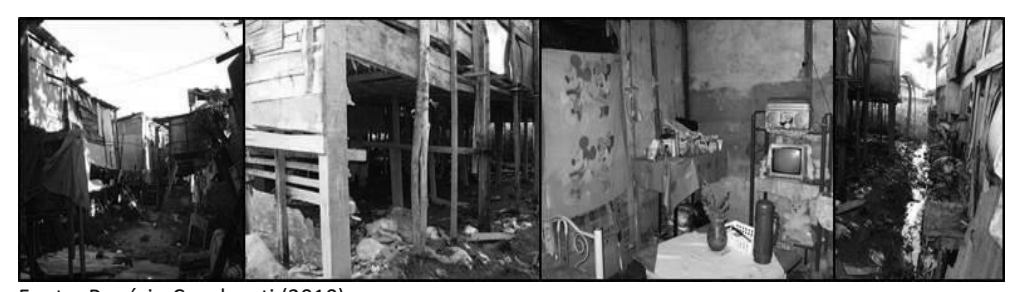

Fonte: Rogério Cavalcanti (2010)

Observando-se a distribuição geral dos conjuntos habitacionais de 2001 a 2016 (Figura 4), verifica-se que grande parte dos conjuntos foi construída em aglomerações de comunidades de interesse social (principalmente os mais recentes na Zona Norte) ou em redondezas desses fragmentos de assentamentos precários, os quais em termos da composição do território ocupam 45,13\% da cidadedo Recife. (PREFEITURA DO RECIFE, 2016).

Figura 4 - Distribuição espacial e evolução temporal da implantação de conjuntos habitacionais em políticas de habitação de interesse social no Recife, de 2001 a 2016

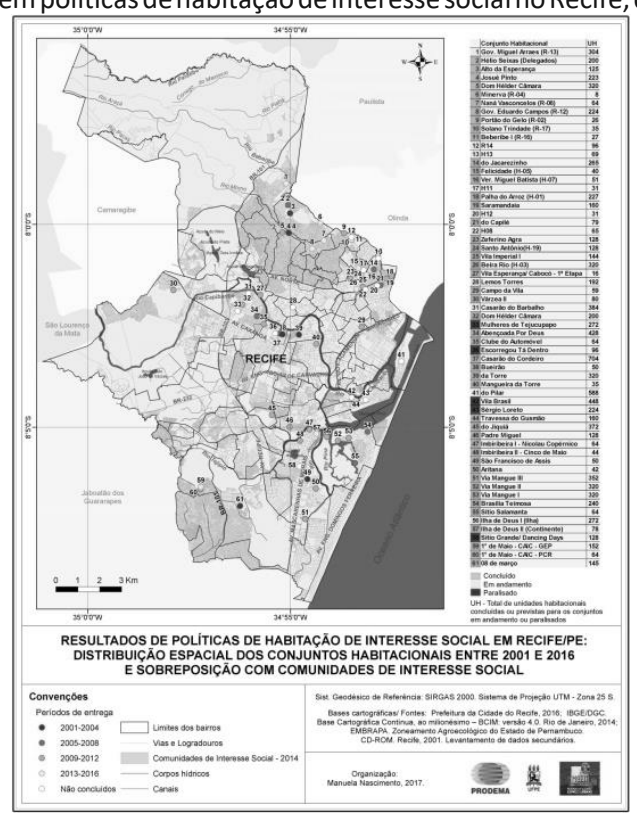

Fonte: Manuela Nascimento (2017). 
Não necessariamente, as pessoas foram realocadas para as proximidades de suas áreas de origem, mas considera-se um fator positivo, que com o tempo, os conjuntos passaram a ser construídos em áreas mais próximas às moradias de origem das populações realocadas. No entanto, pode-se perceber que as construções têm-se concentrado na zona norte e oeste, em áreas pouco valorizadas pelo mercado imobiliário e carentes de infraestrutura urbana.

O posicionamento recente dos conjuntos acompanha tanto à fragmentação social do território recifense, na qual ocorrem vizinhanças extremas, onde convivem espaços elitizados e assentamentos precários, como uma tendência histórica ao deslocamento de comunidades do eixo central. Também é possível observar a concentração dos conjuntos na margem esquerda do Rio Capibaribe, e não na margem direita, onde se encontram os bairros com maior valor do metro quadrado e renda da cidade.

Nas áreas de interesse dos setores empresariais (principalmente as porções centro-leste e sudeste), ainda predominam as lutas por permanência, pois necessariamente, as obras implicam em remoções. Inclusive, observa-se que ospoucos conjuntos alocados nessa região encontram-se com as obras paralisadas devido à falta de recursos, de acordo com técnicos do Governo do Estado e Prefeitura.

Verificada essa distribuição geral, vejamos as condições de acesso aos recursos urbanos, tendo em vista elucidar como estas alocações de natureza política - que aumentam as aglomerações em áreas pobres - dificultam o alcance de boas condições de habitabilidade para pessoas realocadas pela habitação de interesse social, considerada aqui uma condição necessária no alcance ao direito à cidade.

Levando em conta o acesso a esses serviços de uma forma geral, deve-se apresentar um primeiro aspecto com relação a essa área de implantação dos conjuntos: independentemente do quantitativo de unidades de educação e saúde aqui apresentado, é importante ressaltar a elevada demanda preexistente no local. Os conjuntos ocupam uma mancha de treze bairros na Zona Norte do Recife, com uma densidade demográfica muito elevada, de $12.739 \mathrm{hab} / \mathrm{km}^{2}$, considerando os dados do Censo 2010. Também 

POLÍTICAS DE HABITAÇÃO DE INTERESSE SOCIAL

vale destacar que muitas famílias foram realocadas de locais próximos aos conjuntos, diminuindo a geração de novas demandas por serviços.

Porém, principalmente no acesso às unidades de educação, essa proximidade écondicionada pela forma de mobilidade utilizada, sobretudo a pé ou de bicicleta para o deslocamento. Nessas formas, a mudança de uma distância de menos de um quilômetro para acesso ao serviço, para uma distância de dois quilômetros ou mais, pode representar um aumento na demanda por vagas em uma unidade mais próxima a um conjunto ou grupo deles, onde agora se concentra uma população que antes estava distribuída ao longo do rio.

Considerando os 22 conjuntos observados, verificou-se que na area onde ocorre a maior aglomeração de unidades habitacionais, há menos estabelecimentos tanto de serviços de educação, como de saúde. Esta região corresponde à porção mais a sudeste da mancha de bairros (Figuras 5 e 6). Um conjunto habitacional está situado de forma mais isolada, na porção mais ao norte da mancha, e é o conjunto que apresenta menos estabelecimentos em seu entorno. Nas representações a seguir, podem ser visualizados dois detalhes com uma imagem de satélite do ano de 2014, referentes às duas áreas de concentração de conjuntos. Nestas imagens pode-se observar a grande concentração de domicílios na região.

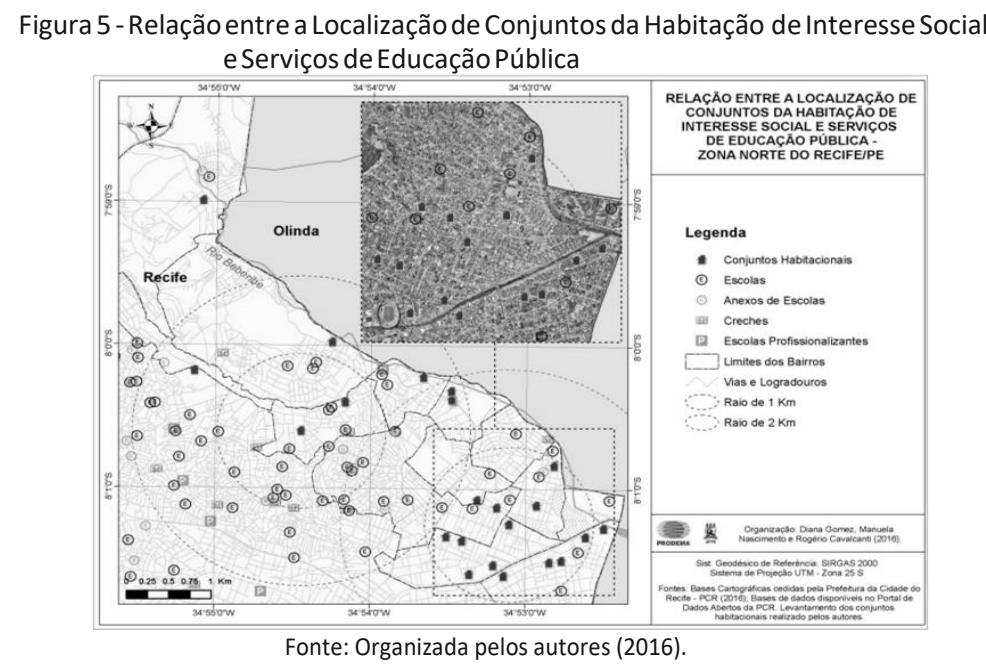


Levando em conta a tipologia dos estabelecimentos de educação pública, observa-se uma boa distribuição das escolas e anexos, mas há poucos estabelecimentos do tipo creche e profissionalizante, e estes, também se encontram concentrados na região onde há menos conjuntos implantados. Num raio de dois quilômetros do centro do maior aglomerado de conjuntos implantados, só há uma creche municipal e nenhum centro profissionalizante.

Quanto aos estabelecimentos de saúde, verifica-se que há unidades de saúde da família distribuídas por toda a mancha, mas há apenas duas policlínicas, uma policlínica com atendimento odontológico e outra com maternidade. Esse fato, naturalmente, impulsiona a população a deslocar-se para as unidades nas áreas centrais da ci- dade, e também para os três hospitais situados no entorno das áreas.

Na medida em que se direciona ao norte da mancha analisada, observa-se que vai diminuindo a diversificação dos estabelecimentos, já que mais a sul e sudoeste, encontram-se uma Unidade deAtenção Integral à Saúde, Farmácia da Família, um Centro de Vigilância Ambiental e os Centros de Atenção Psicossocial (CAPS). As Academias da Cidade situam-se mais ao norte, onde há menos conjuntos. Moradores locais relataram a importância das academias e que as frequentam mesmo tendo que percorrer uma maior distância, contudo, apesar da demanda observada, não há novos projetos previstos para a região.

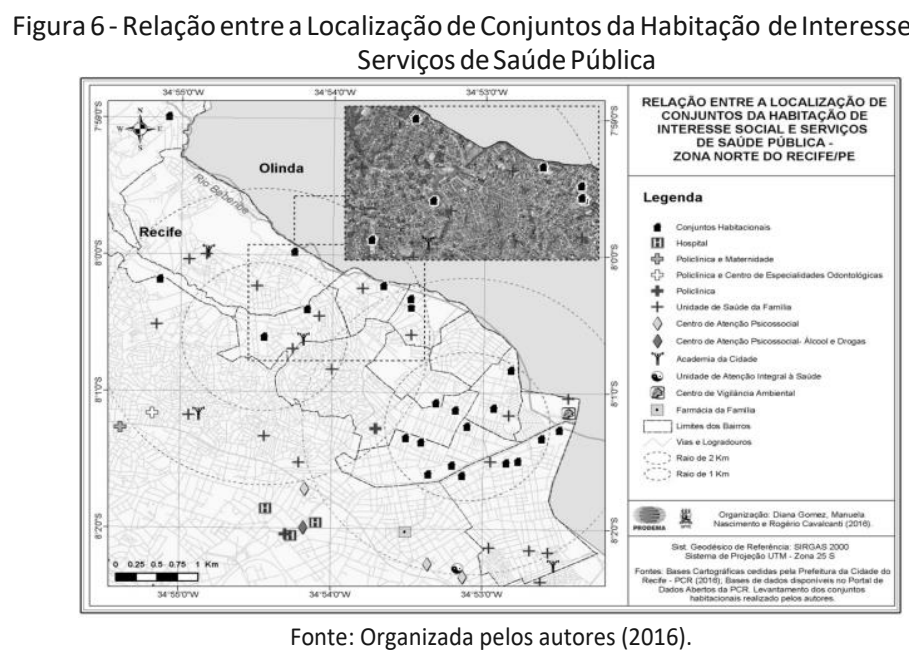


Considerando a dinâmica habitacional da área, evidencia-se que o baixo poder aquisitivo é o principal condicionante na tomada de decisão quanto ao local de moradia para a grande parte da população, uma vez que essas áreas foram sendo historicamente ocupadas por populações de baixa renda. A área tornou-se alvo de intervenções principalmente por conta das deficiências verificadas no saneamento, que afeta tanto o principal curso hídrico local, o Rio Beberibe, como as instalações habitacionais dos que se encontram nas áreas mais precárias, com destaque para a total vulnerabilidade social e ambiental observada nas moradias do tipo palafita.

Em se tratando da provisão habitacional por parte do poder público, nestas modalidades de habitação de interesse social, observa-se que as decisões quanto à localização das moradias ocorrem de forma verticalizada e há pouco acompanhamento da pós-ocupação e das necessidades da população reassentada. Assim, do ponto de vista do local do assentamento das moradias, geram-se elementos que compõem um quadro de conflitos socioespaciais entre os habitantes, uma vez que os novos moradores têm de disputar espaços com os moradores locais que não dispõem de uma prestação de serviços satisfatória.

Nesse sentido, a inclusão principalmente de creches, unidades de saúde (mesmo para atendimentos de menor complexidade, tais como consultas, procedimentos ambulatoriais e vacinações), bem como áreas para prática de esportes e lazer, deve fazer parte do projeto dos habitacionais assim como ocorreu em outras áreas da cidade e não tem sido praticado na área, fato que sobrecarrega as redes existentes.

Na busca de um efetivo direito à cidade nestes conjuntos habitacionais, é preciso considerar as possibilidades de integração desses novos moradores com os moradores mais antigos nas áreas, tanto culturalmente como no acesso às infraestruturas e serviços de educação, saúde e lazer, que eventualmente já estejam disponíveis na área de implantação e que, com o acréscimo repentino dessas pessoas, tornam-se alvo de conflitos e problemas com o aumento das demandas.

\section{CONCLUSÃO}

Na avaliação da implantação dos programas de provisão habitacional, em especial o PAC-Beberibe na cidade do Recife/PE, identificou-se que a aplicabilidade desses programas 
visa, muitas vezes, outras vertentes que não estão ligadas à promoção e à inclusão dos setores mais vulneráveis da população ao acesso à moradia de qualidade, mas tem como mote primordial o controle político e estratégico pelo Estado, inclusive para favorecimento em campanhas eleitorais. A esse respeito, Alves (2009, p. 107) aponta que as primeiras políticas habitacionais visualizadas em território brasileiro tiveram como proposta principal "[...] as múltiplas formas de iludir o povo em troca de votos."

Mesmo apresentando, de forma implícita, o controle político e estratégico pelo Estado, há consequências outras visualizadas a partir da implementação de políticas públicas com a finalidade de melhorar as condições de habitabilidade em assentamentos precários. Esse context produz o processo de periferização e segregação especial a partir do momento em que os conjuntos habitacionais são instalados em áreas onde as infraestruturas de saneamento básico, transporte coletivo, equipamentos comunitários de educação, saúde, lazer e cultura não são efetivados para as populações mais carentes inseridas nos programas habitacionais.

Comisso, podemos observar naáreade atuaçãodo PAC-Beberibe que nos 22 conjuntos habitacionais existe a ausência ou ineficiência de serviços essenciais, a exemplo de unidades educacionais e de saúde, para as populacionais atendidas pelo programa. A isto, somam-se outros problemas, tais como a deterioração da infraestrutura das habitações que foram construídas há pouco mais de cinco anos.

Dessa forma, podemos refletir que para garantir o direito à cidade, sobre a perspectiva de Lefebvre (2008), ou seja, além dos direitos individuais e essenciais, mas como um processo de transformação da sociedade urbana, as políticas habitacionais, em especial as intervenções habitacionais propostas pelo PACBeberibe, devem assegurar de fato às populações atendidas, reais benefícios da vida urbana.

Na continuidade da pesquisa, inserida no contexto das atividades do Grupo de Pesquisa Movimentos Sociais e Espaço Urbano (MSEU), outros elementos serão incorporados à análise, tais como: situação das infraestruturas de mobilidade urbana e acesso ao transporte público, saneamento, lazer e da mobilização comunitária na busca por uma efetiva regularização fundiária dos conjuntos. 


\section{REFERÊNCIAS}

ALVES, P. R. M. Valores do Recife: o valor do solo na evolução da cidade. Recife: Luci Artes Gráficas Ltda., 2009.

BRUNO, L. Poder político e sociedade: qual sujeito, qual objeto? In: BARTOLOZZI, E.; ANDRADE OLIVEIRA, D. (Orgs.). Crise da escola e políticas educativas. Belo Horizonte: Autêntica, 2009.

CARLOS, A. F. A. A questão da habitação na Metrópole de São Paulo. Scripta Nova: Revista Electrónica de Geografía y Ciencias Sociales, Barcelona, v. VII, n. 146(046), ago. 2003. Disponível em:<http:// www.ub.edu/geocrit/sn/sn-146(046).htm>. Acesso: 1 jan. 2014.

HAESBAERT, R. Território e Multiterritorialidade: um debate. GEOgraphia, Niterói, v. 9, n. 17, p. 19-45, 2007. Disponível em:<http://www.uR.br/geographia/ojs/index.php/geographia/article/ view/213>. Acesso em: 1 out. 2014.

HARVEY, D. O direito à cidade. Lutas Sociais, São Paulo, n. 29, p. 73-89, jul./dez. 2012. Traduzido do original em inglês "The right to the city”, por Jair Pinheiro, professor da FFC/UNESP/Marília. Versão cotejada com a publicada na New Left Review, n. 53, 2008. Disponível em:<http://www4.pucsp.br/neils/downloads/neilsrevista- 29-port/david-harvey.pdf>. Acesso: 1 jun. 2016.

LEFEBVRE. H. O direito à cidade. 5. ed. São Paulo: Centauro, 2008.

LEITÃO, G.; ARAÚJO, H. Quando o futuro repete o passado: uma análise dos conjuntos habitacionais produzidos pelo Programa Minha Casa/Minha Vida na Cidade do Rio de Janeiro. Separata: X Seminario Investigación Urbana y Regional, Bogotá, 2013. Disponível em:<http://revistas.javeriana.edu.co/index.php/cvyu/article/ view/5919/4782>. Acesso em: 1 set. 2015.

LITTLE, P. Territórios sociais e povos tradicionais no Brasil: por uma antropologia da territorialidade. Brasília, DF: Universidade de Brasília, Instituto de Ciências Sociais, Departamento de Antropologia, 2002. (Série Antropológica, n. 322). Disponível em:<http://nute.ufsc. br/bibliotecas/upload/paullittle.pdf >. Acesso em: 1 out. 2014.

MARICATO, E. Por um novo enfoque teórico na pesquisa sobre habitação. Cadernos Metrópole, São Paulo, v. 21, p. 33-52, 2009. Disponível em: $<$ http://www.cadernosmetropole.net/download/cm artigos/cm21_147.pdf>. Acesso: 1 out. 2015.

NASCIMENTO, M. M. P.; BAUTISTA, D. C. G. Habitação 
popular e "de interesse social" no Recife: da liga social contra o mocambo à persistência na passagem para os grandes conjuntos habitacionais. Revista Movimentos Sociais e Dinâmicas Socioespaciais, Recife, v. 5, n. 2, dez. 2016. Disponível

em:<http://www.revista.ufpe.br/ revistamseu/index.php/revista/article/view/165>. Acesso em: 1 jan. 2017.

PREFEITURA DO RECIFE. Atlas das infraestruturas públicas das comunidades de interesse social do Recife. Recife, 2016. Disponível em:<http://mundosafari.com.br/projetos/2015/prefeitura-atlas/. Acesso: out. 2016.

RAFFESTIN, C. Por uma geografia do poder. São Paulo: Ática, 1993. (Serie Temas, v. 29. Geografia e politica).

ROLNIK, R.; NAKANO, K. As armadilhas do pacote habitacional. Le monde diplomatique Brasil, São Paulo, mar. 2009. Disponível em:<http://www.diplomatique.org.br/artigo.php?id=46>. Acesso em: 24 out. 2015.

SANTOS, M. A urbanização brasileira. 5. ed. São Paulo: EDUSP, 2005. (Coleção Milton Santos, v. 6).

Metamorfoses do espaço habitado: fundamentos teóricos e metodológicos da geografia. 3. ed. São Paulo: Hucitec, 1997.

SILVA, L. J. A. da. Segregação urbana e instrumentos de acesso à moradia no Brasil e na França. Revista Movimentos Sociais e Dinâmicas Espaciais, Recife, v. 4, n.1, nov. 2015. Disponível em:<http://www.revista.ufpe.br/revistamseu/index.php/revista/article/ view/136>. Acesso em: 1 jan. 2017.

SOUZA, M. J. L. de. O território: sobre espaço e poder, autonomia e desenvolvimento. In: CASTRO, I. E. de et al. Geografia: conceitos e temas. 3. ed. Rio de Janeiro: Bertrand Brasil, 2001. p. 77-116.

VASCONCELOS, P. A aplicação do conceito de segregação residencial ao contexto brasileiro na longa duração. Cidades, Presidente Prudente, SP, v. 1, n. 2, p. 259-274, 2004. Disponível em:<http://revista.fct.unesp.br/index.php/revistacidades/article/ viewFile/478/508>. Acesso em: 1 abr. 2015. 